\title{
What determines medical students' career preference for general practice residency training?: a multicenter survey in Japan
}

Kenya le $e^{1,2^{*}}\left(\mathbb{D}\right.$, Akiko Murata ${ }^{3}$, Masao Tahara $^{4}$, Manabu Komiyama ${ }^{5}$, Shuhei Ichikawa ${ }^{6}$, Yousuke C. Takemura ${ }^{2,6}$ and Hirotaka Onishi ${ }^{7}$

\begin{abstract}
Background: Few studies have systematically explored factors affecting medical students' general practice career choice. We conducted a nationwide multicenter survey (Japan MEdical Career of Students: JMECS) to examine factors associated with students' general practice career aspirations in Japan, where it has been decided that general practice will be officially acknowledged as a new discipline.

Methods: From April to December 2015, we distributed a 21-item questionnaire to final year medical students in 17 medical schools. The survey asked students about their top three career preferences from 19 specialty fields, their demographics and their career priorities. Multivariable logistic regression was used to determine the effect of each item.

Results: A total of 1264 responses were included in the analyses. The top three specialty choice were internal medicine: 833 (65.9\%), general practice: 408 (32.3\%), and pediatrics: 372 (29.4\%). Among demographic factors, "plan to inherit other's practice" positively associated with choosing general practice, whereas "having physician parent" had negative correlation. After controlling for potential confounders, students who ranked the following items as highly important were more likely to choose general practice: "Clinical diagnostic reasoning (adjusted odds ratio (aOR): 1.65, 95\% Cl 1.40-1.94)","community-oriented practice (aOR: 1.33, 95\% Cl 1.13-1.57)", and" involvement in preventive medicine (aOR: 1.18, 95\% Cl 1.01-1.38)". On the contrary, "acute care rather than chronic care", "mastering advanced procedures", and "depth rather than breadth of practice" were less likely to be associated with general practice aspiration.
\end{abstract}

Conclusions: Our nationwide multicenter survey found several features associated with general practice career aspirations: clinical diagnostic reasoning; community-oriented practice; and preventive medicine. These results can be fundamental to future research and the development of recruitment strategies.

Keywords: General practice, Primary care, Family practice, Career choice, Medical students, Surveys and questionnaires

\section{Background}

Family medicine training in Asian countries has been developed mostly in partnership with other western countries since the 1970s. Commonwealth member countries like Singapore and Malaysia have started family

\footnotetext{
${ }^{*}$ Correspondence: iekenya0321@gmail.com

${ }^{1}$ Department of General Internal Medicine, Kawasaki Municipal

Tama Hospital/St. Marianna University School of Medicine, 1-30-37

Shukugawara, Kawasaki, Kanagawa 214-8525, Japan

Full list of author information is available at the end of the article
}

medicine training several decades ago, whereas other nations have established it more recently [1].

Japanese physicians have been board certified by the individual society of their specialty. Although ex-specialists have played a major role in Japanese primary care, there was no formal family medicine training until recently [11]. Starting in 2018, however, a new board certificate system for physicians' specialties by a thirdparty organization will be implemented. Along with this reform, it has been decided that general practice, 
including family medicine, will be officially acknowledged as a new basic discipline. Based on such historical context, it is anticipated that the number of applicants for general practice will increase among medical students and interns.

In Europe and North America, accumulating evidence has elucidated factors associated with choosing family medicine and general practice as a career among medical students and junior doctors. Within the existing literature on medical career choice, several demographic factors have been shown to positively influence the choice of general practice/family medicine: being female [2-5], coming from rural background $[2,5,6]$, having no family members in the healthcare field $[6,7]$. In addition to the demographic factors, career intentions such as interest in broad scope practice [7-9], interest in communityoriented practice [10, 11], work-life balance [11-13], and societal orientation [6-8] have consistently predicted general practice/family medicine career choice.

On the contrary, few studies have systematically explored factors affecting specialty choice of Japanese medical students and junior doctors, especially in general practice/family medicine. Our previous qualitative study revealed a range of factors affecting the choice of family medicine as their specialty including but not limited to "community/rural orientedness" and "multifaceted orientation" [11]. More recently, a cross-sectional study at a Japanese university revealed that admission from hometown, intent for rural practice, and work-life balance were positive influences, while presence of medical relatives and scientific orientation were negatively associated with general practice career choice [14]. To our knowledge, however, no multicenter study has been conducted with a focus on general practice aspiration under the new board certificate system.

The purpose of this study was to conduct a nationwide multicenter survey (Japan MEdical Career of Students: JMECS) to examine factors associated with general practice career aspirations among Japanese medical students.

\section{Methods \\ Study population}

From April to December 2015, 17 medical schools (14 public schools and three private schools) which were selected by convenience sampling and gave permission for study participation were included in the survey. We distributed a 21-item questionnaire to medical students who had enrolled in their final year at the time of April 2015 in the 17 medical schools. We were able to sample approximately $21 \%$ of 81 medical schools in Japan in 2015.

\section{Measurement}

The items included in the questionnaire were determined based on a literature review [2-14], including our previous qualitative study results, and discussion among the study team. Given the paucity of existing evidence in a Japanese context, we included items thought to reflect the uniqueness of Japanese general practice. The survey asked students to select top three career options from 19 newly determined specialty fields as an outcome variable: internal medicine, pediatrics, dermatology, psychiatry, surgery, orthopedics, obstetrics and gynecology, ophthalmology, otorhinolaryngology, urology, neurosurgery, radiology, anesthesiology, pathology, clinical laboratory, emergency medicine, plastic surgery, rehabilitation, and general practice. The other explanatory variables included participant demographics (e.g. age, sex) and 14 questions regarding their career intention, using 6-point Likert scales ranging from 1 (strongly disagree) to 6 (strongly agree). All the data collected from medical students were anonymous except for the name of the medical school. Before the data were handed over to the researchers, the school names were coded and de-identified by an honest broker using a linking file.

\section{Statistical analysis}

The outcome variable was dichotomized into two categories based on whether general practice was included in up to three choices or not. Among explanatory variables, "sex", "job or other field experiences prior to medical school", "having physician parent", and "plan to inherit other's practice" were treated as binary; "birthplace" was treated as nominal, and "age" was treated as a continuous variable. The responses to the Likert scale of 14 career intention questions were treated as continuous, assuming that the variables have interval properties. Univariable and multivariable logistic regression were used to examine the effect of each demographic factor and career intentions in terms of odds ratio and 95\% confidence intervals. We considered $\mathrm{p}$ values less than or equal to 0.05 as significant. STATA SE14.0 was used for all analyses. Since the generation of parsimonious model was not our primary objective, only the saturated model was fitted in our logistic regression analyses. Hosmer-Lemeshow Goodness of Fit test was applied to test the overall model fit. Multicollinearity was tested based on variance inflation factor with a cutoff of 10. Model discrimination was tested using c-statistics.

The study protocol was approved by the Institutional Ethical Committee of Mie University Graduate School of Medicine (No. 1482). 


\section{Results}

A total of 1408 responses out of a possible 1903 medical students $(74.0 \%)$ in the 17 medical schools were obtained. Among them, 1264 responses were included in the final analyses after removing invalid or insufficient responses. Distribution of the participants' sex, age, birth place, job or other field experiences prior to medical school, physician parent, plan to inherit other's practice, and career priorities are shown in Table 1. The survey participants had a median age of $24,66.3 \%$ were male, $32.1 \%$ had a physician parent, and $11.3 \%$ had a positive intent to inherit an existing practice. Among the students with an intention to inherit, $92.3 \%$ had a physician parent. On the contrary, only $32.5 \%$ of participants with a physician parent revealed their intention to inherit. The top five specialty fields chosen by students and their numbers were internal medicine 833 (65.9\%), general practice 408 (32.3\%), pediatrics $372(29.4 \%)$, surgery 344 (27.2\%), and emergency medicine 244 (19.3\%).

Univariate analysis found those born in suburban areas compared to urban areas, and not having a physician parent, both had significant effects on students' general practice career preference (Table 2). However, after adjusting for other covariates in the multivariable logistic regression, "having a physician parent" and "intent to inherit existing practice" had a negative association with choosing general practice among the medical students demographics (Table 2).

As for the 14 career priorities, seven positive influences and six negative influencers were identified in crude (or univariate) analyses (Table 2). After adjusting for other covariates in the multivariable logistic regression, three positive influencers and three negative influencers remained significant. Medical students who ranked "clinical diagnostic reasoning", "community-oriented practice", and "involvement in preventive medicine" as highly important were more likely to choose general practice, whereas "acute care rather than chronic care", "mastering advanced procedures", and "depth rather than breadth of practice" were less likely to be associated with general practice aspiration (Table 2).

Table 1 Characteristics of GP candidates and non-GP candidates among Japanese medical student

\begin{tabular}{|c|c|c|c|}
\hline & Total $(\mathrm{N}=1264)$ & $\mathrm{GP}(\mathrm{N}=405)$ & Non-GP $(\mathrm{N}=846)$ \\
\hline \multicolumn{4}{|l|}{ Demographics; no. (\%) of students } \\
\hline Age, median (range), years & $24(23-58)$ & $24(23-58)$ & $24(23-52)$ \\
\hline Sex (male) & $838(66.3)$ & $274(67.2)$ & $564(65.9)$ \\
\hline \multicolumn{4}{|l|}{ Hometown } \\
\hline Urban & $267(21.1)$ & $72(17.7)$ & $195(22.8)$ \\
\hline Relatively urban & $287(22.7)$ & $102(25)$ & $185(21.6)$ \\
\hline Relatively rural & $401(31.7)$ & $130(31.9)$ & $271(31.7)$ \\
\hline Rural & $309(24.5)$ & $104(25.5)$ & $205(24)$ \\
\hline Other academic or professional experiences prior to medical school & $286(22.6)$ & $102(25)$ & $184(21.5)$ \\
\hline Physician parent & $406(32.1)$ & $114(27.9)$ & $292(34.1)$ \\
\hline Intent to inherit existing practice & $143(11.3)$ & $55(13.5)$ & $88(10.3)$ \\
\hline \multicolumn{4}{|l|}{ Career priorities $^{\mathrm{a}}$; mean (SD) } \\
\hline Mastering advanced procedures & $4.83(1.00)$ & $4.60(1.03)$ & $4.93(0.97)$ \\
\hline Work life balance & $4.89(0.93)$ & $4.90(0.89)$ & $4.89(0.95)$ \\
\hline Frequent patient communication & $4.82(0.89)$ & $5.01(0.82)$ & $4.73(0.91)$ \\
\hline Opening own clinic & $3.33(1.35)$ & $3.48(1.34)$ & $3.26(1.35)$ \\
\hline Involvement in preventive medicine & $4.06(1.13)$ & $4.40(1.04)$ & $3.90(1.14)$ \\
\hline Involvement in terminal care & $3.77(1.15)$ & $4.06(1.03)$ & $3.63(1.17)$ \\
\hline Acute care rather than chronic care & $4.11(1.06)$ & $3.96(1.02)$ & $4.18(1.07)$ \\
\hline Not treat patients with psychosocial problems & $2.75(1.19)$ & $2.50(1.14)$ & $2.87(1.19)$ \\
\hline Income & $4.17(1.00)$ & $4.04(1.08)$ & $4.23(0.96)$ \\
\hline Access to advanced medical fields & $4.28(0.98)$ & $4.06(0.97)$ & $4.39(0.96)$ \\
\hline Clinical diagnostic reasoning & $4.31(1.00)$ & $4.60(0.95)$ & $4.17(0.99)$ \\
\hline Depth rather than breadth of practice & $3.97(1.02)$ & $3.64(0.97)$ & $4.13(1.01)$ \\
\hline Involvement in global health & $3.37(1.13)$ & $3.45(1.13)$ & $3.32(1.12)$ \\
\hline Community-oriented practice & $4.09(1.05)$ & $4.47(0.98)$ & $3.91(1.03)$ \\
\hline
\end{tabular}

\footnotetext{
a Please select one of the following options which best describes your thoughts regarding your career priorities." ( $1=$ strongly disagree, $6=$ strongly agree)
} 
Table 2 Crude and adjusted odds ratio of characteristics of GP candidates among Japanese medical students ( $N=1264)$

\begin{tabular}{|c|c|c|}
\hline OR $(95 \% \mathrm{Cl})$ & Crude & Adjusted \\
\hline \multicolumn{3}{|l|}{ Demographics } \\
\hline Sex (male) & $0.94(0.74,1.21)$ & $0.85(0.64,1.15)$ \\
\hline \multicolumn{3}{|l|}{ Hometown } \\
\hline Urban & - & - \\
\hline Relatively urban & $1.49^{*}(1.04,2.15)$ & $1.45(0.96,2.17)$ \\
\hline Relatively rural & $1.30(0.92,1.83)$ & $1.24(0.85,1.83)$ \\
\hline Rural & $1.37(0.96,1.97)$ & $1.25(0.84,1.88)$ \\
\hline Other academic or professional experiences prior to medical school & $1.22(0.92,1.61)$ & $1.23(0.90,1.68)$ \\
\hline Physician parent & $0.75^{*}(0.58,0.96)$ & $0.59 *(0.42,0.83)$ \\
\hline Intent to inherit existing practice & $1.36(0.95,1.95)$ & $1.64^{*}(1.01,2.68)$ \\
\hline \multicolumn{3}{|l|}{ Career priorities } \\
\hline Mastering advanced procedures & $0.72^{*}(0.64,0.81)$ & $0.75^{*}(0.65,0.87)$ \\
\hline Work life balance & $1.02(0.90,1.15)$ & $0.89(0.76,1.06)$ \\
\hline Frequent patient communication & $1.47^{*}(1.28,1.70)$ & $1.17(0.97,1.42)$ \\
\hline Opening own clinic & $1.13^{*}(1.03,1.23)$ & $1.08(0.95,1.22)$ \\
\hline Involvement in preventive medicine & $1.51^{*}(1.35,1.70)$ & $1.18^{*}(1.01,1.38)$ \\
\hline Involvement in terminal care & $1.41(1.26,1.58)$ & $1.10(0.95,1.28)$ \\
\hline Acute care rather than chronic care & $0.82^{*}(0.73,0.92)$ & $0.85^{*}(0.74,0.98)$ \\
\hline Not treat patients with psychosocial problems & $0.76^{*}(0.68,0.84)$ & $0.91(0.80,1.04)$ \\
\hline Income & $0.83^{*}(0.73,0.93)$ & $0.92(0.79,1.08)$ \\
\hline Access to advanced medical fields & $0.70 *(0.62,0.80)$ & $0.85(0.71,1.02)$ \\
\hline Clinical diagnostic reasoning & $1.60^{*}(1.40,1.82)$ & $1.65^{*}(1.40,1.94)$ \\
\hline Depth rather than breadth of practice & $0.61^{*}(0.54,0.69)$ & $0.69 *(0.59,0.81)$ \\
\hline Involvement in global health & $1.11^{*}(1.00,1.23)$ & $1.03(0.90,1.18)$ \\
\hline Community-oriented practice & $1.77^{*}(1.55,2.01)$ & $1.33^{*}(1.13,1.57)$ \\
\hline
\end{tabular}

Dependent variable: whether general practice was included in up to three choices (1) or not (0)

Adjusted pseudo $\mathrm{R}^{2}=0.1572 ; \mathrm{AIC}=1.093329$

* Statistically significant at an alpha level of 0.05

\section{Discussion}

The survey participants revealed a similar distribution of age and gender to a national sample of recent medical school graduates in Japan [15]. Among the study participants, general practice was selected as one of the career options by approximately $32 \%$ of medical students in their final year. "Clinical diagnostic reasoning", "community-oriented practice", and "involvement in preventive medicine" were positively associated with the selection of general practice. A student's community orientation has been shown to predict primary care career preference and was a factor affecting family medicine career choice among Japanese physicians [11]. On the contrary, the ranking of "acute care rather than chronic care", "mastering advanced procedures", and "depth rather than breadth of practice" as of higher importance were less likely to be associated with an aspiration for general practice aspiration. This has been described in other studies [13].

Of 14 career priorities, "clinical diagnostic reasoning" was the strongest predictor of general practice choice, a finding not common in previous literatures. In many Japanese medical schools, the department of general practice or family medicine has been in charge of teaching fundamental clinical reasoning skills to medical students. Such context could have contributed to the strong positive association between clinical diagnostic reasoning and general practice choice among study participants.

Two demographic factors, "having physician parent" and "plan to inherit other's practice", were found to have significant association with choosing general practice, even after controlling for other covariates. Having physician parent was negatively associated with general practice choice, which is concordant with existing literature $[6,7]$ from North America and Europe. One potential reason is that the perceived prestige of other medical specialties among physician parents could negatively influence their children's general practice choice. On the other hand, having family or friends in general practice was found to have positive association with general practice career choice in a study [15]. Thus, it is possible that 
the effect of family physicians may vary according to the specialty of parents. A positive association between the intention to inherit existing practice and general practice choice would have reflected students' perceived usefulness of general practice residency to develop expertise as a future private practice owner.

Some previously known demographic factors, such as being female [2-5] and coming from rural background $[2,5,6]$, had no association between students' general practice choice. In our study, participants were asked to select the degree of rurality of their birthplace based on subjective judgment. This could be attributed to the heterogeneity of birthplace classification, which potentially could have led to a null result. In addition, the different definition of rural areas among countries should be taken into consideration for future research.

The role of gender in career choice has been well studied and is known to be affected by nationality. A qualitative study explored Japanese female doctors' perspectives on specialty choice and found that they tend to make a choice based on conventional gender roles where women tend to spend more time on household duties [16]. It is possible that general practice, which is not well-established yet in Japan, could have been perceived as too unpredictable and insecure a career path. Such insecurities of general practice career could have been perceived as an unreasonable choice for female medical students. While family medicine preference at entry to medical school is known to increase the likelihood of choosing a family medicine career $[7,8]$, this item was not included in our study as we assumed that a general practice career path had not been widely available at the time of study participants' medical school entry.

Our results reflect how general practice is perceived by medical students, and they are a little different from that in other countries where general practice/family medicine is well-established. Further studies are required to confirm factors affecting students' career choice to determine strategies to facilitate general practice career choice in Japan.

\section{Limitations}

Despite the thorough development of the questionnaire and relatively large sample size, our study has several limitations. First of all, our outcome measurement was career aspiration during the final year of medical school. Thus, the actual enrolment in general practice residency and subsequent retention rate should also be considered in the future. Secondly, due to convenience sampling of medical schools, the representativeness of our study results to the general medical student population would be limited. In addition, the study results may not be generalizable to other countries. To our knowledge, however, this is the first and largest nationwide survey conducted across multiple Japanese medical schools.

\section{Conclusions}

Our nationwide multicenter survey found several important factors associated with general practice career aspirations among Japanese medical students. Clinical diagnostic reasoning, community-oriented practice, and preventive medicine were three major career priorities among students selected general practice. These results can be fundamental to future research and the development of recruitment strategies.

\section{Abbreviations \\ JMECS: Japan MEdical Career of Students; OR: odds ratio.}

\section{Authors' contributions}

$\mathrm{KI}, \mathrm{AM}, \mathrm{MT}, \mathrm{MK}, \mathrm{SI}, \mathrm{YCT}$, and $\mathrm{HO}$ participated in the proposal's design and data collection. Kl, AM, MT, MK, and SI carried out the data analyses and drafted the manuscript. YCT and $\mathrm{HO}$ reviewed process of data analyses and manuscript writing. All authors read and approved the final manuscript.

\section{Author details \\ ${ }^{1}$ Department of General Internal Medicine, Kawasaki Municipal Tama Hospital/St. Marianna University School of Medicine, 1-30-37 Shukugawara, Kawasaki, Kanagawa 214-8525, Japan. ${ }^{2}$ Department of Family Medicine, Mie University School of Medicine, 2-174 Edobashi, Tsu-shi, Mie 514-8507, Japan. ${ }^{3}$ Family Practice Center of Okayama, 292-1 Toyosawa, Katsuta-gun, Nagi-cho, Okayama 708-1323, Japan. ${ }^{4}$ Iwakura Station Tahara Clinic, 291-1 Chuzaiji, Iwakura, Sakyo-ku, Kyoto-shi, Kyoto 606-0021, Japan. ${ }^{5}$ Thank You All, Family Clinic Hiratsuka, 215-3 Okazaki, Hiratsuka-shi, Kanagawa 259-1212, Japan. ${ }^{6}$ Department of Education and Research in Family and Community Medicine, Mie University Graduate School of Medicine, 2-174 Edobashi, Tsu-shi, Mie 514-8507, Japan. ${ }^{7}$ International Research Center for Medical Education, Gradu- ate School of Medicine, The University of Tokyo, 7-3-1, Hongo, Bunkyo-ku, Tokyo 113-0033, Japan.}

\section{Acknowledgements}

We would like to thank the respondents of our survey for their support. We would also like to thank the faculty and staff in the 17 medical schools for their assistance with questionnaire survey, the secretariat of Japan Primary Care

Association for data management, and Nippon Foundation for their support.

\section{Competing interests}

The authors declare that they have no competing interests.

\section{Availability of data and materials}

The datasets used and/or analysed during the current study are available from the corresponding author on reasonable request.

Consent for publication

Not applicable.

Ethics approval and consent to participate

The study protocol was approved by the Institutional Ethical Committee of Mie University Graduate School of Medicine (No. 1482). The IRB Committee waived the requirement to obtain a signed consent from study participants to avoid the potential risks of breach of confidentiality.

\section{Funding}

This study was funded by the Japan Primary Care Association (Grant Number 26-01-001). 


\section{Publisher's Note}

Springer Nature remains neutral with regard to jurisdictional claims in published maps and institutional affiliations.

Received: 1 May 2017 Accepted: 22 January 2018

Published online: 27 January 2018

\section{References}

1. Arya N, Gibson C, Ponka D, et al. Family medicine around the world: overview by region: the Besrour Papers: a series on the state of family medicine in the world. Can Fam Phys. 2017;63(6):436-41.

2. Senf JH, Campos-Outcalt D, Kutob R. Factors related to the choice of family medicine: a reassessment and literature review. J Am Board Fam Pract. 2003;16(6):502-12. https://doi.org/10.3122/jabfm.16.6.502.

3. Bland C, Meurer L, Maldonado G. Determinants of primary care specialty choice: a non-statistical meta-analysis of the literature. Acad Med. 1995;70(7):620-41.

4. Kost A, Cawse-Lucas J, Evans DV, Overstreet F, Andrilla CH, Dobie S. Medical student participation in family medicine department extracurricular experiences and choosing to become a family physician. Fam Med. 2015:47(10):763-9. http://ovidsp.ovid.com/ovidweb.cgi?T=JS\&PAGE=ref erence\&D=medl\&NEWS $=$ N\&AN $=26545052$.

5. Gill H, McLeod S, Duerksen K, Szafran O. Factors influencing medical students' choice of family medicine: effects of rural versus urban background. Can Fam Phys. 2012;58(11):649-57.

6. Avery DM, Wheat JR, Mcknight JT, Leeper JD. Factors associated with choosing family medicine as a career specialty : what can we use? Am J Clin Med. 2009;6(4):54-8. http://aapsus.org/articles/40.pdf.

7. Scott I, Gowans M, Wright B, Brenneis F, Banner S, Boone J. Determinants of choosing a career in family medicine. CMAJ. 2011;183(1):1-8. https:// doi.org/10.1503/cmaj.091805.
8. Wright B, Scott I, Woloschuk W, Brenneis F. Career choice of new medical students at three Canadian universities: family medicine versus specialty medicine. CMAJ. 2004;170(13):1920-4. https://doi.org/10.1503/ cmaj.1031111.

9. Kassebaum DG, Szenas PL. Factors influencing the specialty choices of 1993 Medical School Graduates. Acad Med. 1994;69(2):164-70.

10. Whitcomb ME. Primary care medicine in the United States: where are we headed? Acad Med. 2002;77(8):759-60.

11. Ie K, Tahara M, Murata A, Komiyama M, Onishi H. Factors associated to the career choice of family medicine among Japanese physicians: the dawn of a new era. Asia Pac Fam Med. 2014:13(1):11. https://doi.org/10.1186/ s12930-014-0011-2.

12. Weiss $\mathrm{YG}$, Zisk-Rony RY, Tandeter $\mathrm{H}$, et al. Using medical specialty and selection criteria clusters to study specialty selection by Israeli medical students. BMC Med Educ. 2017;17(1):17. https://doi.org/10.1186/ s12909-017-0854-y.

13. Osborn HA, FrcsC KF, Brandt MG, Doyle PC. Primary care specialty career choice among Canadian medical students Understanding the factors that influence their decisions Recherche Le choix d'une carrière en médecine de première ligne chez les étudiants en médecine canadiens. Can Fam Phys. 2017:63:107-13.

14. Kawamoto R, Ninomiya D, Kasai Y, et al. Factors associated with the choice of general medicine as a career among Japanese medical students. Med Educ Online. 2016;21:29448. https://doi.org/10.3402/meo.v21.29448.

15. Deutsch T, Lippmann S, Frese T, Sandholzer H. Who wants to become a general practitioner? Student and curriculum factors associated with choosing a GP career-a multivariable analysis with particular consideration of practice-orientated GP courses. Scand J Prim Health Care. 2015:33(1):47-53. https://doi.org/10.3109/02813432.2015.1020661.

16. Nakamura M. Studies on work-and-life balances and career development of Japanese physicians. Roudo Shakai-gaku Kenkyu. 2010;11:37-61.

\section{Submit your next manuscript to BioMed Central and we will help you at every step:}

- We accept pre-submission inquiries

- Our selector tool helps you to find the most relevant journal

- We provide round the clock customer support

- Convenient online submission

- Thorough peer review

- Inclusion in PubMed and all major indexing services

- Maximum visibility for your research

Submit your manuscript at www.biomedcentral.com/submit
() Biomed Central 